\title{
Thermally Modified Titania Photocatalysts for Phenol Removal from Water
}

\author{
Joanna Grzechulska-Damszel, Antoni W. Morawski, and Barbara Grzmil \\ Institute of Chemical Technology and Environment Engineering, Szczecin University of Technology, Pułaskiego 10, \\ 70-322 Szczecin, Poland
}

Received 28 April 2006; Revised 19 June 2006; Accepted 28 June 2006

Two kinds of titanium dioxide were used as starting materials for thermal modification: Tytanpol A11 supplied by Chemical Factory "Police" S.A. (Poland) and Degussa P25 supplied by Degussa AG (Germany). The photocatalytic activity of titania materials modified by thermal treatment was tested in the reaction of photocatalytic oxidation of phenol. It was found that the highest activity in the reaction of photocatalytic decomposition of phenol, in case of Tytanpol A11, shows the samples of material modified at temperatures of 700 and $750^{\circ} \mathrm{C}$. These catalysts were more active than untreated A11, whereas materials modified at higher temperatures show lower activity. In the case of P25, all thermally treated materials were less active than the unmodified material. The photocatalyst samples were characterized by UV-Vis/DR, FTIR/DRS, and XRD methods.

Copyright (c) 2006 Joanna Grzechulska-Damszel et al. This is an open access article distributed under the Creative Commons Attribution License, which permits unrestricted use, distribution, and reproduction in any medium, provided the original work is properly cited.

\section{INTRODUCTION}

Heterogeneous photocatalysis has been shown to be an effective method for removing a wide range of organic compounds from water [1-22]. Titanium dioxide is the most widely used material in the photocatalytic reactions. $\mathrm{TiO}_{2}$ has three types of crystal structures: anatase, rutile, and brookite. The most common phases are anatase and rutile, the former of which is more stable with lower temperature. It is known that anatase is transformed into rutile at temperatures around $700-800^{\circ} \mathrm{C}$, which differ depending upon the various perturbing parameters of particles free energy, that is, particle size and impurity dosing [23].

In recent years there has been a great deal of research on the optimization of the catalytic properties of titanium dioxide used in the photodegradation of organic pollutants in water. In many studies it has been found that the activity of the titania catalyst depended on its preparation method, particle size, reactive surface area, incident light intensity, crystal structure and $\mathrm{pH}$ of solution. The crystal structure and crystallinity of titania particles are important factors that determine photoactivity. Many researchers reported that the anatase form of titania is more reactive than the rutile one [24-26]. Pelizzetti et al. [27] have correlated the photoactivity of the catalyst with the morphological aspects. Tanaka et al. [26] have reported the correlation of the crystallographic phase of titania with its catalytic activity during the degra- dation of a number of organic compounds such as benzene, chloroacetic acid, benzoic acid, and phenol. Ohtani et al. [28] reported that the photoactivity of amorphous titania was negligible due to recombination of photoexcited electronhole pairs at defects located on the surface and in the bulk of particles and increased linearly with the weight fraction of anatase and further improved by calcination of completely crystallized powder. Bickley et al. [29] reported that the photoactivity of the mixed phase of titania was greater than pure anatase crystalline. Fotou and Pratsinis [30] also reported that the anatase form of titania containing some rutile is most reactive in destroying phenol.

In this paper, Tytanpol A11 titanium dioxide, which is mainly anatase form of titania, was thermally treated in order to obtain a partial transformation of anatase to rutile phase and this way increase the photocatalytic activity of this material.

The photocatalytic activity of titania materials was tested in the reaction of photocatalytic oxidation of phenol.

\section{MATERIALS AND METHODS}

\subsection{Chemicals}

Two kinds of titanium dioxide were used as starting materials for thermal modification: Tytanpol A11 supplied by Chemical Factory "Police" S.A. (Poland) and Degussa P25 supplied 
TABLE 1: The basic properties of Tytanpol A11 and Degussa P25 photocatalysts.

\begin{tabular}{lcccc}
\hline Photocatalyst & Crystallite phase & $\begin{array}{c}\text { Specific } \\
\text { surface area } \\
{\left[\mathrm{m}^{2} \mathrm{~g}^{-1}\right]}\end{array}$ & $\begin{array}{c}\text { Average pore } \\
\text { diameter } \\
{[\mathrm{nm}]}\end{array}$ & $\begin{array}{c}\text { Band gap } \\
\text { energy } \\
{[\mathrm{ev}]}\end{array}$ \\
\hline A11 & Anatase + rutile: $8.4 / 1.6 \%$ & 11.4 & 7.7 & 3.31 \\
P25 & Anatase + rutile: $81.7 / 18.3 \%$ & 52 & 6.9 & $3.42 / 3.12$ \\
\hline
\end{tabular}

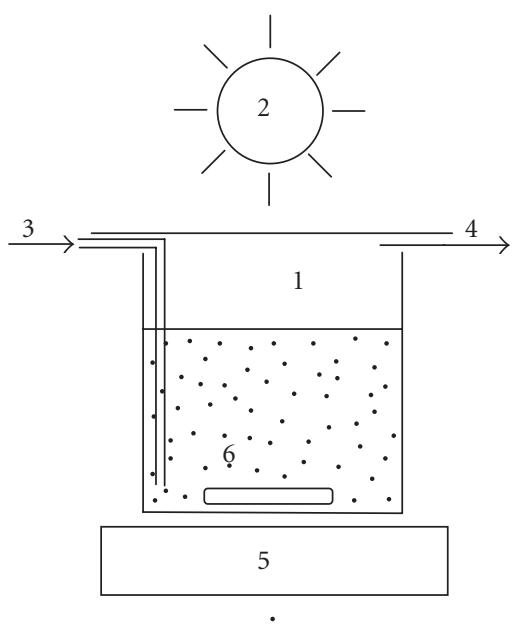

FIgURE 1: The scheme of apparatus for the photocatalytic reactions. (1) Batch photoreactor, $(2)$ light source, $(3,4)$ gas inlet and outlet, (5) magnetic stirrer, (6) reaction mixture.

by Degussa AG (Germany). The basic properties of these materials are presented in Table 1.

Phenol, which was chosen as a model organic compound for activity tests, was supplied by POCH S.A. Company (Poland).

\subsection{Titania modification}

Tytanpol A11 and Degussa P25 were thermally treated in air atmosphere. The weighed samples of particular materials were placed in the furnace and heated in the air atmosphere at the temperatures of 700, 750, 800, 850, 900, 950, and $100^{\circ} \mathrm{C}$. Samples were placed in the heated furnace and were held at a particular temperature for one hour.

\subsection{Activity tests}

The photocatalytic activity of obtained materials was verified in the reaction of photocatalytic decomposition of phenol which was chosen as a model organic compound.

The process of photocatalytic oxidation of phenol was conducted in the batch reactor with an internal light source and the photocatalyst suspended in the solution. The scheme of the apparatus is presented in Figure 1.

$500 \mathrm{~cm}^{3}$ of phenol solution and a particular amount of photocatalyst were placed in the reactor. The reactor contents were aerated and mixed with a magnetic stirrer. The reaction mixture was irradiated with a lamp emitting UV-A and visible light. The radiation intensity of the lamp is $270 \mathrm{~W} \mathrm{~m}^{-2}$. Tests were performed with a constant amount of particular photocatalyst $-0.2 \mathrm{~g} \mathrm{dm}^{-3}$ and with concentration of the solution of $100 \mathrm{mg}$ of phenol/ $\mathrm{dm}^{3}$. The reaction mixture was stirred for $15 \mathrm{~min}$ before illumination for adsorption of phenol on the photocatalyst surface.

The samples of reaction mixture were taken from the reactor, at appropriate time intervals, in order to monitor the phenol concentration in the solution. The photocatalyst was separated from the slurry by filtration with PVDF membrane filter (pore diameter $0.45 \mu \mathrm{m}$ ) and the solution was analyzed by the UV-VIS method using a JASCO V-530 spectrometer.

\subsection{Characteristics of the photocatalytic materials}

The photocatalyst samples were characterized by UV-Vis/DR technique using a Specord M40 spectrometer (Carl Zeiss Jena, Germany) equipped with an integrating sphere accessory for diffuse reflectance measurements. $\mathrm{BaSO}_{4}$ was used as a reference.

The surface properties of the photocatalysts were examined by FTIR analysis. Measurements were performed using JASCO FTIR 430 spectrometer (Japan) equipped with a diffuse reflectance accessory (Harrick, USA).

The phase composition was analyzed by X-ray diffraction analysis (X'Pert PRO Philips diffractometer) using a $\mathrm{CuK}_{\alpha}$ radiation.

\section{RESULTS AND DISCUSSION}

Tytanpol A11 and Degussa P25 differ essentially in properties. Their activity in photocatalytic processes is also different-Degussa P25 usually shows higher activity in these processes. One of the reasons for activity difference is the phase composition. Degussa P25 is a mixture of two phases: anatase and rutile with a ratio of about 80 to $20 \%$ while Tytanpol A11 contains only about $1.5 \%$ of rutile. Changes in the crystallographic structure of titanium dioxide from anatase to rutile occur during thermal treatment.

The photocatalytic activity of titania materials modified by thermal treatment was tested in the reaction of photocatalytic oxidation of phenol. It was found that, in case of Tytanpol A11, the highest activity in the reaction of photocatalytic decomposition of phenol shows the samples of material modified at temperatures of 700 and $750^{\circ} \mathrm{C}$. These catalysts were more active than untreated A11 whereas materials modified at higher temperatures show lower activity. In the case of P25, all thermally treated materials were less active 


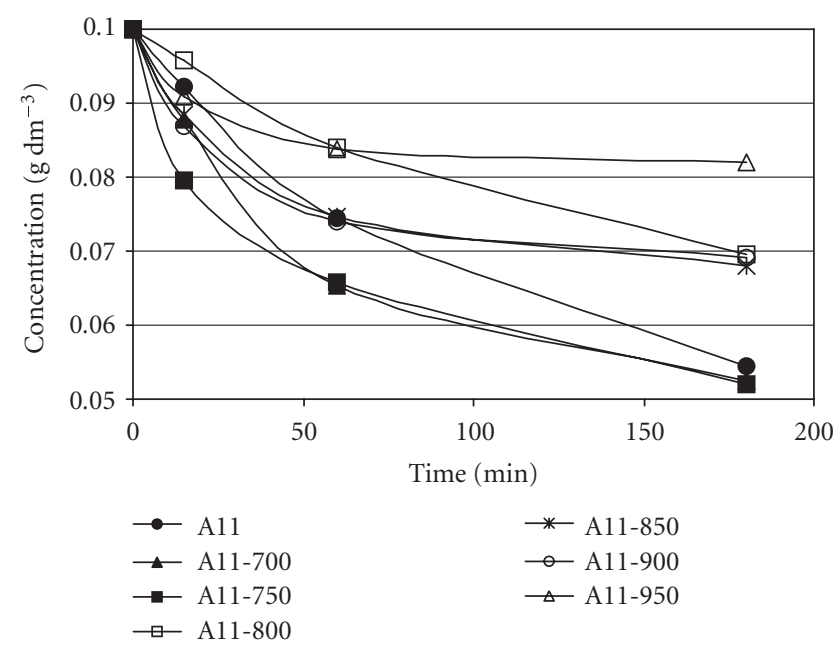

FIGURE 2: Changes in concentration of phenol during the photocatalytic reaction for A11 photocatalyst samples. Initial concentration of phenol $-0.1 \mathrm{~g} \mathrm{dm}^{-3}$, photocatalyst amount $-0.2 \mathrm{~g} \mathrm{dm}^{-3}$.

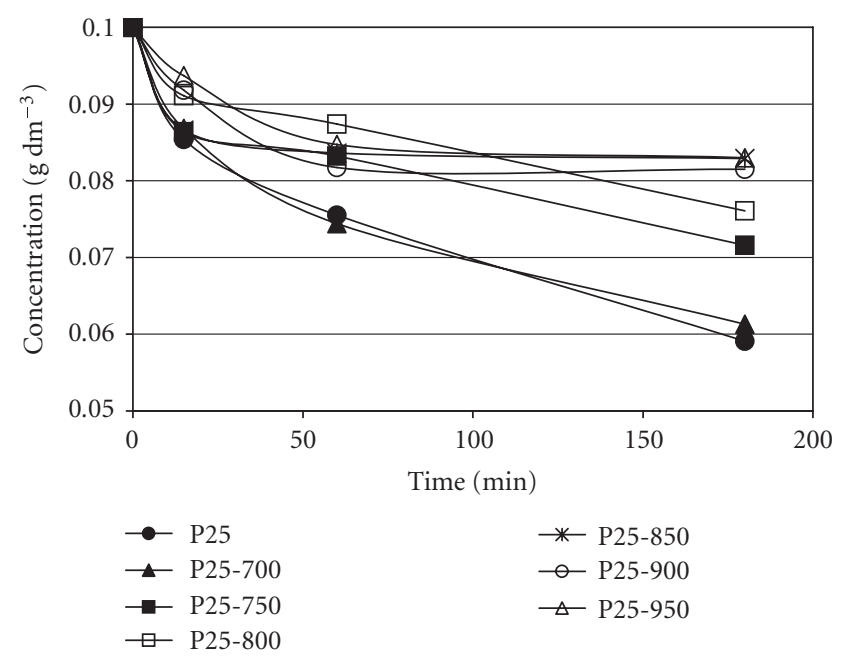

Figure 3: Changes in concentration of phenol during the photocatalytic reaction for $\mathrm{P} 25$ photocatalyst samples. Initial concentration of phenol $-0.1 \mathrm{~g} \mathrm{dm}^{-3}$, photocatalyst amount $-0.2 \mathrm{~g} \mathrm{dm}^{-3}$.

than the unmodified material. The results of these experiments are presented in Figures 2 and 3.

$\mathrm{XRD}$ analysis was done to determine the phase composition of photocatalysts. Table 2 presents the obtained results. The relative abundance of anatase and rutile phases were calculated from the (101) reflection of anatase and the (110) reflection of rutile. The background of obtained X-ray patterns (not shown in this paper) is flat, and the peaks are very sharp and narrow indicating good crystallinity of analyzed samples.

As can be seen for A11 photocatalyst, rutile percentage slightly increase up to $900^{\circ} \mathrm{C}$. Substantial increase of the rutile phase occurs for the sample treated at $950^{\circ} \mathrm{C}$ and for the
TABLE 2: The phase composition of A11 and P25 samples.

\begin{tabular}{lcc}
\hline & \% of anatase & \% of rutile \\
\hline A11 & 98.4 & 1.6 \\
A11/700 & 98.6 & 1.4 \\
A11/750 & 98.5 & 1.5 \\
A11/800 & 98.3 & 1.7 \\
A11/850 & 97.9 & 2.1 \\
A11/900 & 96.3 & 3.7 \\
A11/950 & 65.2 & 34.8 \\
A11/1000 & 33.0 & 67.0 \\
P25 & 81.7 & 18.3 \\
P25/700 & 21.9 & 78.1 \\
P25/750 & 1.7 & 98.3 \\
P25/800 & 0.0 & 100.0 \\
P25/850 & 0.0 & 100.0 \\
P25/900 & 0.0 & 100.0 \\
P25/950 & 0.0 & 100.0 \\
P25/1000 & 0.0 & 100.0 \\
\hline
\end{tabular}

sample treated at $1000^{\circ} \mathrm{C}$ it is still bigger. However total conversion from anatase to rutile was not observed.

For P25 photocatalyst, $100 \%$ of rutile was found already for the sample treated at $800^{\circ} \mathrm{C}$.

Such a difference in phase transformation can be explained by the presence of additional components in Tytanpol A11 material. As a final step of production a surface treatment is applied. For this treatment $\mathrm{Al}(\mathrm{OH})_{3}$ and $\mathrm{SiO}_{2}$ are used. Presumably these additives can prevent anatase-rutile transformation.

An important parameter of catalysts used in the photocatalytic processes is the band gap energy. The lower is the value of the band gap energy, the wider range of irradiation can activate the photocatalyst.

The band gap energies $(\mathrm{Eg})$ of the photocatalysts were calculated according to the equation:

$$
\mathrm{Eg}=h \frac{c}{\lambda}
$$

where Eg is the band gap energy $(\mathrm{eV}), h$ the Planck's constant, $c$ the light velocity $(\mathrm{m} / \mathrm{s})$, and $\lambda$ is the wavelength $(\mathrm{nm})$.

The thermal treatment influenced the changes in the band gap energy for both A11 and P25 photocatalysts.

Figure 4 shows derivatives obtained from UV-Vis/DR spectra for P25 photocatalyst. As can be seen from Figure 4, for untreated P25 photocatalyst, two outlined maximums of absorption can be observed at 362.68 and $396.70 \mathrm{~nm}$. For thermally treated samples, there is only one maximum which shifts toward higher wavelength with increasing treatment temperature. The values of band gap energies are presented in Table 3.

Figure 5 shows derivatives obtained from UV-Vis/DR spectra for A11 photocatalyst. As can be seen, for untreated A11 there is one maximum of absorption at 374.58 . Spectra of thermally treated samples are more sophisticated. With effect from temperature of $700^{\circ} \mathrm{C}$, appearance of the second maximum can be observed. It is clearly outlined after 
TABLE 3: The band gap energies of A11 and P25 samples.

\begin{tabular}{lccccc}
\hline & $\begin{array}{c}\text { Eg1 } \\
{[\mathrm{eV}]}\end{array}$ & $\begin{array}{c}\text { Eg2 } \\
{[\mathrm{eV}]}\end{array}$ & & $\begin{array}{c}\text { Eg1 } \\
{[\mathrm{eV}]}\end{array}$ & $\begin{array}{c}\text { Eg2 } \\
{[\mathrm{eV}]}\end{array}$ \\
\hline A11 & 3.31 & - & $\mathrm{P} 25$ & 3.42 & 3.12 \\
A11/700 & 3.33 & 3.11 & P25/700 & - & 3.10 \\
A11/750 & 3.32 & 3.10 & P25/750 & - & 3.08 \\
A11/800 & 3.32 & 3.09 & P25/800 & - & 3.08 \\
A11/850 & 3.31 & 3.09 & P25/850 & - & 3.05 \\
A11/900 & 3.35 & 3.08 & P25/900 & - & 3.05 \\
A11/950 & 3.39 & 3.06 & P25/950 & - & 3.02 \\
A11/1000 & 3.39 & 3.05 & P25/1000 & - & 3.01 \\
\hline
\end{tabular}

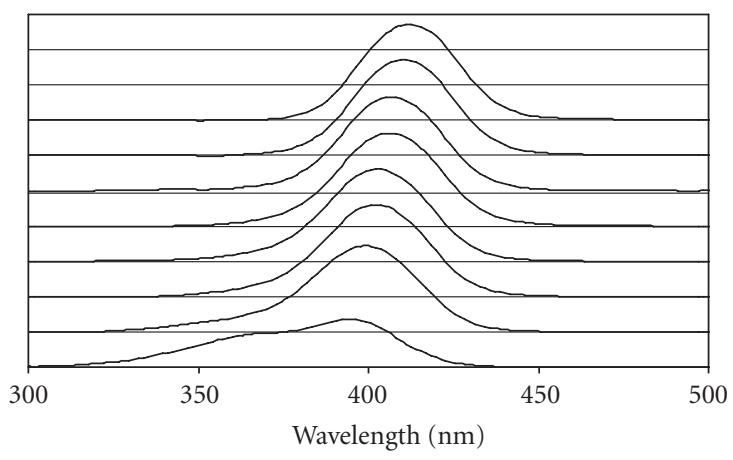

Figure 4: Derivatives obtained from UV-Vis/DR spectra for P25 photocatalyst samples. From bottom to top: untreated P25, P25/ $700^{\circ} \mathrm{C}, \mathrm{P} 25 / 750^{\circ} \mathrm{C}, \mathrm{P} 25 / 800^{\circ} \mathrm{C}, \mathrm{P} 25 / 850^{\circ} \mathrm{C}, \mathrm{P} 25 / 900^{\circ} \mathrm{C}, \mathrm{P} 25 / 950^{\circ} \mathrm{C}$, $\mathrm{P} 25 / 1000^{\circ} \mathrm{C}$.

deconvolution of the spectra. The values of band gap energies are presented in Table 3.

$\mathrm{UV}-\mathrm{Vis} / \mathrm{DR}$ spectra were also recorded for a mixture of anatase and rutile model compounds. The following mechanical mixtures were prepared: $100 \%$ rutile, $90 \%$ rutile $+10 \%$ anatase, $80 \%$ rutile $+20 \%$ anatase, $70 \%$ rutile + $30 \%$ anatase, $60 \%$ rutile $+40 \%$ anatase, $50 \%$ rutile $+50 \%$ anatase, $40 \%$ rutile $+60 \%$ anatase, $30 \%$ rutile $+70 \%$ anatase, $20 \%$ rutile $+80 \%$ anatase, $10 \%$ rutile $+90 \%$ anatase, $100 \%$ anatase. Spectra of these mixtures are presented in Figure 6. $100 \%$ anatase and $100 \%$ rutile spectra have one maximum of absorption at $374.58 \mathrm{~nm}$ and $403.73 \mathrm{~nm}$, respectively. Their mixtures show either two sharply outlined maximums or there can be seen a bulging at the spectra where the second peak appears. After deconvolution of the spectra, two peaks can be clearly seen. With the increasing amount of anatase phase in the mixtures, the absorption peak derived from rutile at about $390-400 \mathrm{~nm}$ diminishes and an arise of the peak that belongs to the anatase phase at about $360-370 \mathrm{~nm}$ can be observed. Therefore it was found that the material which is a mixture of two phases of titania, like P25, shows two maximums of absorption and consequently two band gap energies.

In order to determine the effect of thermal treatment on surface properties of the titania materials the FTIR/DRS spectra of the photocatalysts before and after modification

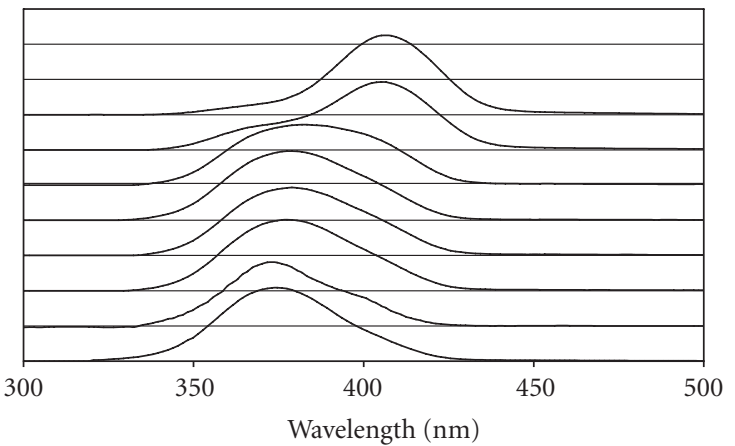

FIgURE 5: Derivatives obtained from UV-Vis/DR spectra for A11 photocatalyst samples. From bottom to top: untreated A11, $\mathrm{A} 11 / 700^{\circ} \mathrm{C}, \mathrm{A} 11 / 750^{\circ} \mathrm{C}, \mathrm{A} 11 / 800^{\circ} \mathrm{C}, \mathrm{A} 11 / 850^{\circ} \mathrm{C}, \mathrm{A} 11 / 900^{\circ} \mathrm{C}, \mathrm{A} 11 /$ $950^{\circ} \mathrm{C}, \mathrm{A} 11 / 1000^{\circ} \mathrm{C}$.

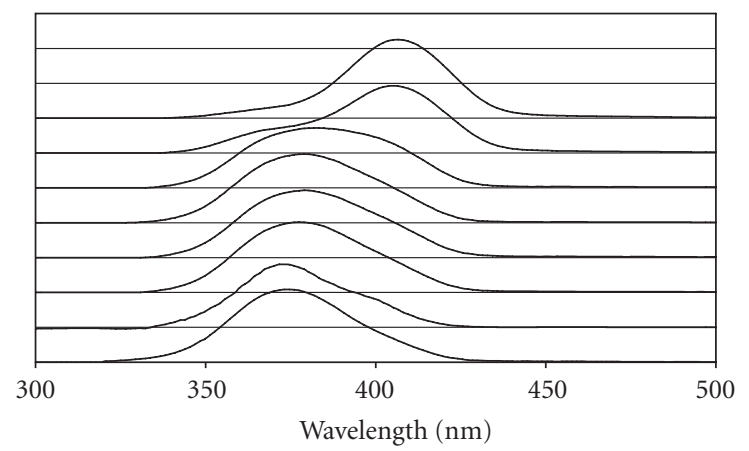

Figure 6: Derivatives obtained from UV-Vis/DR spectra of model mixtures of anatase and rutile. From bottom to top: 100\% rutile, $90 \%$ rutile $+10 \%$ anatase, $80 \%$ rutile $+20 \%$ anatase, $70 \%$ rutile + $30 \%$ anatase, $60 \%$ rutile $+40 \%$ anatase, $50 \%$ rutile $+50 \%$ anatase, $40 \%$ rutile $+60 \%$ anatase, $30 \%$ rutile $+70 \%$ anatase, $20 \%$ rutile + $80 \%$ anatase, $10 \%$ rutile $+90 \%$ anatase, $100 \%$ anatase.

were recorded. FTIR/DRS spectra are presented in Figures 7 and 8.

The obtained spectra show a clear absorption band corresponding to stretching vibrations of water [31, 32]. Broad bands in the range of $3600-2600 \mathrm{~cm}^{-1}$, with a maximum at about $3400 \mathrm{~cm}^{-1}$, are assigned to symmetric and asymmetric vibrations of water molecules coordinated to $\mathrm{TiO}^{4+}$ cations $[33,34]$. The literature data indicates that the intensity of these bands decrease with increasing temperature and this fact is connected to the partial removal of adsorbed water [33]. It can be seen that the intensity of the mentioned band is higher for some of thermally treated samples which negate the literature data. However it can be assumed that the thermal treatment of $\mathrm{TiO}_{2}$ in air atmosphere contribute to the formation of new $-\mathrm{OH}$ groups in amount exceeding the amount of desorbed water effecting in increase of the bands in the range of $3600-2600 \mathrm{~cm}^{-1}$. In the case of P25 photocatalyst, appearance of clear band at about $3420 \mathrm{~cm}^{-1}$ can be observed. This band is characteristic for adsorbed water $[31,32]$. The bands corresponding to $-\mathrm{OH}$ groups 


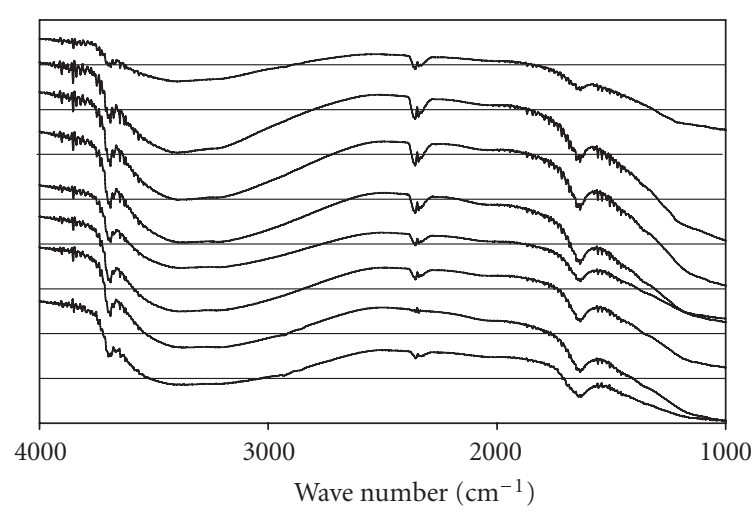

Figure 7: FTIR spectra for A11 photocatalyst samples. From bottom to top: untreated $\mathrm{P} 25, \mathrm{P} 25 / 700^{\circ} \mathrm{C}, \mathrm{P} 25 / 750^{\circ} \mathrm{C}, \mathrm{P} 25 / 800^{\circ} \mathrm{C}$, $\mathrm{P} 25 / 850^{\circ} \mathrm{C}, \mathrm{P} 25 / 900^{\circ} \mathrm{C}, \mathrm{P} 25 / 950^{\circ} \mathrm{C}, \mathrm{P} 25 / 1000^{\circ} \mathrm{C}$.

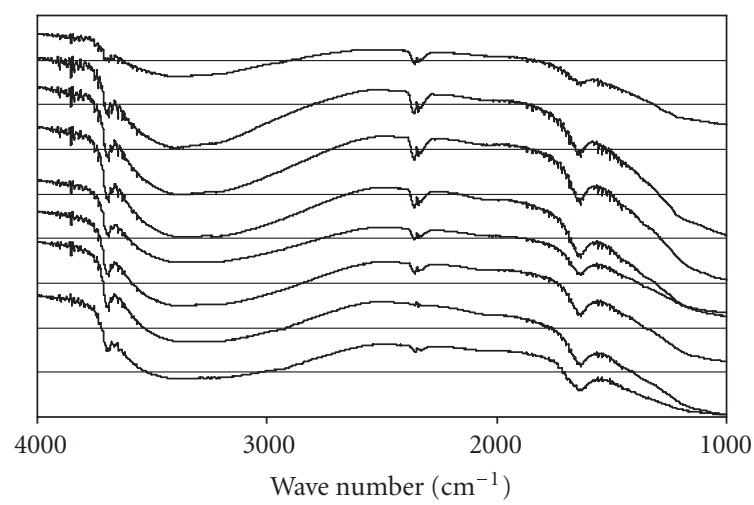

Figure 8: FTIR spectra for P25 photocatalyst samples. From bottom to top: untreated $\mathrm{P} 25, \mathrm{P} 25 / 700^{\circ} \mathrm{C}, \mathrm{P} 25 / 750^{\circ} \mathrm{C}, \mathrm{P} 25 / 800^{\circ} \mathrm{C}$, $\mathrm{P} 25 / 850^{\circ} \mathrm{C}, \mathrm{P} 25 / 900^{\circ} \mathrm{C}, \mathrm{P} 25 / 950^{\circ} \mathrm{C}, \mathrm{P} 25 / 1000^{\circ} \mathrm{C}$.

vibrations can be observed at $1660-1650 \mathrm{~cm}^{-1}$. In this case, thermal treatment also resulted in increase of intensity of these bands (up to $750^{\circ} \mathrm{C}$ and subsequent decrease for higher temperatures). It is more visible in case of A11 photocatalyst. Presumably, the new active sites formed on the surface of the photocatalyst resulting in higher activity of modified A11 photocatalyst.

Figures 9 and 10 show the spectra of used photocatalysts. After 35 hours of the reaction of photocatalytic decomposition of phenol, the photocatalyst was separated and dried followed by FTIR analysis.

As can be seen for A11 photocatalyst the spectra before and after the reaction are practically the same.

In the case of P25 photocatalyst there are apparent changes in the spectra. The new absorption bands appeared in the range of $1600-1400 \mathrm{~cm}^{-1}$ and also in the range of $2900-2700 \mathrm{~cm}^{-1}$. These bands can be assigned to $\mathrm{C}-\mathrm{H}$ and $\mathrm{C}=\mathrm{O}$ bonds indicating the presence of carbon deposits formed on the catalyst surface. The presence of carbon deposits could also be seen by the naked eye since the catalyst changed the coloration. The same absorption bands assigned

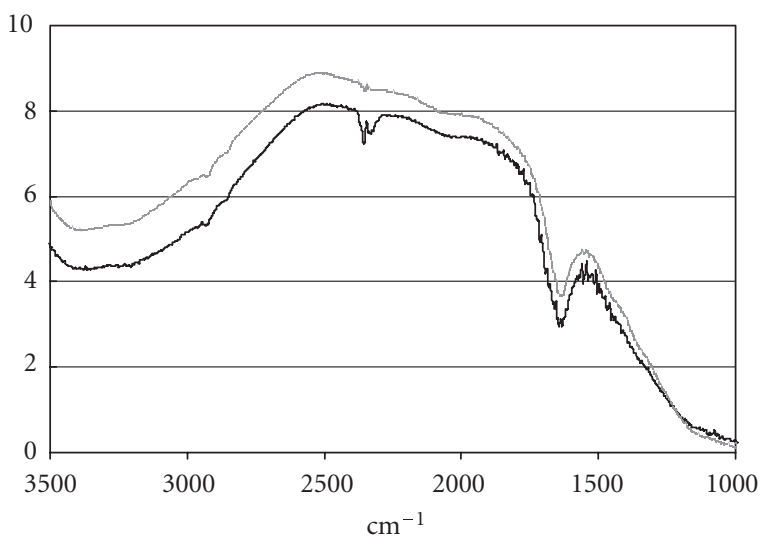

- A11 fresh
A11 used

FIgURE 9: FTIR spectra of fresh and used A11 photocatalysts.

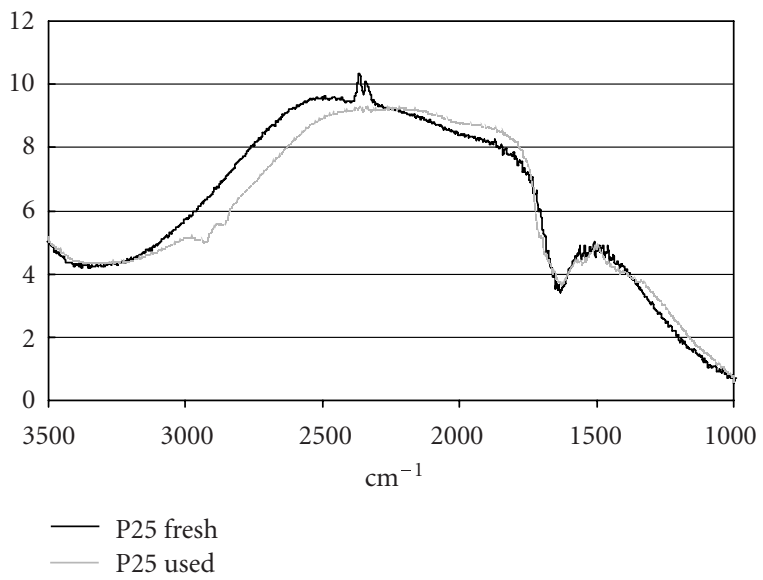

FIgURE 10: FTIR spectra of fresh and used P25 photocatalysts.

to carbon deposits formation was also observed by Einaga et al. [35] during oxidation of hydrocarbons in the presence of illuminated $\mathrm{TiO}_{2}$.

\section{CONCLUSIONS}

The obtained results showed that the increase of the treatment temperature resulted in transformation of anatase to rutile phase in the treated materials. In the case of Degussa P25 transformation was completed already at the temperature of $800^{\circ} \mathrm{C}$ whereas for Tytanpol A11, total transformation was not observed even at the temperature of $1000^{\circ} \mathrm{C}$. This behavior can be explained by the presence of additives in Tytanpol A11 material and also by the low surface area and low rutile content in this material.

The thermal treatment caused changes in the band gap energies for both A11 and P25 photocatalysts. In the case of P25, a double absorption peak was observed only for untreated material and with effect from temperature of $700^{\circ} \mathrm{C}$ there is only one absorption peak which shifts toward higher 
wavelength with increasing treatment temperature. For A11 material, there is only one absorption peak for untreated sample and an arise of the second one is observed beginning with the temperature of $700^{\circ} \mathrm{C}$.

Temperature treatment also resulted in the changes in surface properties recorded by FTIR analysis. The new absorption bands assigned to - $\mathrm{OH}$ groups were observed, especially in the case of A11 samples. Formation of these bands can be connected with generation of the new active sites on the surface of the photocatalyst resulting in higher activity of modified A11 photocatalyst.

The activity test conducted in the reaction of photocatalytic oxidation of phenol showed that the most active samples were the samples of A11 treated at temperatures of 700 and $750^{\circ} \mathrm{C}$. These samples have the same phase composition as untreated Tytanpol A11 - about $98.5 \%$ of anatase and $1.5 \%$ of rutile. UV-Vis analysis of these samples showed a rise of the second absorption peak derived from rutile presence at about 390-400 nm.

Although the literature data most often indicate Degussa P25 as the most active photocatalytic material and the rutile content about $20 \%$ is usually considered as the optimal amount for the best photocatalytic performance, this study did not confirm these results. The photocatalytic activity is a complex effect and many factors have to be put together to obtain a desirable result.

\section{REFERENCES}

[1] M. Schiavello, Photocatalysis and Environment: Trends and Applications, vol. 283 of NATO ASI Series C, Kluwer Academic, London, UK, 1987.

[2] W. Wesley Eckenfelder, A. R. Bowers, and J. A. Bowers, "Chemical oxidation: technologies for the nineties," in Proceedings of the 1st International Symposium on Chemical Oxidation, vol. 1-3, Nashville, Tenn, USA, February 1991.

[3] D. F. Ollis and H. Al.-Ekabi, Photocatalytic Purification and Treatment of Water and Air, Elsevier, Amsterdam, The Netharlands, 1993.

[4] M. R. Hoffmann, S. T. Martin, W. Choi, and D. W. Bahnemann, "Environmental applications of semiconductor photocatalysis," Chemical Reviews, vol. 95, no. 1, pp. 69-96, 1995.

[5] A. L. Linsebigler, G. Lu, and J. T. Yates Jr., "Photocatalysis on $\mathrm{TiO}_{2}$ surfaces: principles, mechanisms, and selected results," Chemical Reviews, vol. 95, no. 3, pp. 735-758, 1995.

[6] M. Chiarello, Heterogeneous Photocatalysis, John Wiley \& Sons, New York, NY, USA, 1997.

[7] D. M. Blake, "Bibliography of work on the photocatalytic removal of hazardous compounds from water and air, update number 2, to October 1996," NREL/TP-430-22197, Golden, CO: National Renewable Energy Laboratory, available from the National Technical Information Service, Springfield, VA 22161NERL/TP-430-22197, Golden Co., 1997.

[8] A. Mills and S. LeHunte, "An overview of semiconductor. Photocatalysis," Journal of Photochemistry and Photobiology A Chemistry, vol. 108, pp. 1-35, 1997.

[9] U.S. Environmental Protection Agency, Handbook: Advanced Photochemical Oxidation Processes, United States Environmental Protection Agency Publication EPA/625/R-98/004, Center for Environmental Research Information, National Risk Man- agement Research Laboratory, Office of Research and Development, Cincinnati, Ohio, USA, 1998.

[10] J.-M. Herrmann, "Heterogeneous photocatalysis: fundamentals and applications to the removal of various types of aqueous pollutants," Catalysis Today, vol. 53, no. 1, pp. 115-129, 1999.

[11] D. F. Ollis, "Photocatalytic purification and remediation of contaminated air and water," Comptes Rendus de l'Academie des Sciences - Series IIC: Chemistry, vol. 3, no. 6, pp. 405-411, 2000.

[12] O. M. Alfano, D. Bahnemann, A. E. Cassano, R. Dillert, and R. Goslich, "Photocatalysis in water environments using artificial and solar light," Catalysis Today, vol. 58, no. 2, pp. 199-230, 2000.

[13] A. Fujishima, T. N. Rao, and D. A. Tryk, "Titanium dioxide photocatalysis," Journal of Photochemistry and Photobiology C: Photochemistry Reviews, vol. 1, no. 1, pp. 1-21, 2000.

[14] D. S. Bhatkhande, V. G. Pangarkar, and A. A. C. M. Beenackers, "Photocatalytic degradation for environmental applicationsa review," Journal of Chemical Technology and Biotechnology, vol. 77, no. 1, pp. 102-116, 2002.

[15] M. Kaneko and I. Okura, Photocatalysis: Science and Technology, Kodansha, Tokyo, Japan; Springer, Berlin, Germany, 2002.

[16] S. Esplugas, J. Gimenez, S. Contreras, E. Pascual, and M. Rodriguez, "Comparison of different advanced oxidation processes for phenol degradation," Water Research, vol. 36, no. 4, pp. 1034-1042, 2002.

[17] A. Mills and S.-K. Lee, "A web-based overview of semiconductor photochemistry-based current commercial applications," Journal of Photochemistry and Photobiology A: Chemistry, vol. 152, no. 1-3, pp. 233-247, 2002.

[18] P. R. Gogate and A. B. Pandit, "A review of imperative technologies for wastewater treatment I: oxidation technologies at ambient conditions," Advances in Environmental Research, vol. 8, no. 3-4, pp. 501-551, 2004.

[19] S. Malato, J. Blanco, A. Vidal, and C. Richter, "Photocatalysis with solar energy at a pilot-plant scale: an overview," Applied Catalysis B: Environmental, vol. 37, no. 1, pp. 1-15, 2002.

[20] J. Blanco and S. Malato, Solar Detoxification, UNESCO, Paris, France, 2003.

[21] S. Malato, J. Blanco, A. Vidal, et al., "Applied studies in solar photocatalytic detoxification: an overview," Solar Energy, vol. 75, no. 4, pp. 329-336, 2003.

[22] H. Chen, C. Chen, and H. Jeng, Water Supply, vol. 13, p. 29, 1995.

[23] S. Kittaka, K. Matsuno, and S. Takahara, "Transformation of ultrafine titanium dioxide particles from rutile to anatase at negatively charged colloid surfaces," Journal of Solid State Chemistry, vol. 132, no. 2, pp. 447-450, 1997.

[24] S.-I. Nishimoto, S. B. Ohtani, H. Kajiwara, and T. Kagiya, "Correlation of the crystal structure of titanium dioxide prepared from titanium tetra-2-propoxide with the photocatalytic activity for redox reactions in aqueous propan-2-ol and silver salt solutions," Journal of the Chemical Society, Faraday Transactions, vol. 81, no. 1, pp. 61-68, 1985.

[25] M. A. Fox and M. T. Dulay, "Heterogeneous photocatalysis," Chemical Reviews, vol. 93, no. 1, pp. 341-357, 1993.

[26] K. Tanaka, T. Hisanaga, and A. P. Rivera, "Photocatalytic purification and treatment of water and air," in Proceedings of the 1st International Conference on $\mathrm{TiO}_{2}$ Photocatalytic Purification and Treatment of Water and Air, D. F. Ollis and H. AlEkabi, Eds., pp. 169-178, Elsevier, Amsterdam, The Netherlands, 1993. 
[27] E. Pelizzetti, C. Minero, E. Borgarello, L. Tinucci, and N. Serpone, "Photocatalytic activity and selectivity of titania colloids and particles prepared by the sol-gel technique: photooxidation of phenol and atrazine," Langmuir, vol. 9, no. 11, pp. 2995-3001, 1993.

[28] B. Ohtani, Y. Ogawa, and S.-I. Nishimoto, "Photocatalytic activity of amorphous-anatase mixture of titanium(IV) oxide particles suspended in aqueous solutions," Journal of Physical Chemistry B, vol. 101, no. 19, pp. 3746-3752, 1997.

[29] R. I. Bickley, T. Gonzalez-Carreno, J. S. Lees, L. Palmisano, and R. J. D. Tilley, "A structural investigation of titanium dioxide photocatalysts," Journal of Solid State Chemistry, vol. 92, no. 1, pp. 178-190, 1991.

[30] G. P. Fotou and S. E. Pratsinis, "Photocatalytic destruction of phenol and salicylic acid with aerosol-made and commercial titania powders," Chemical Engineering Communications, vol. 151, pp. 251-269, 1996.

[31] T. Ivanova and A. Harizanova, "Characterization of $\mathrm{TiO}_{2}$ and $\mathrm{TiO}_{2}-\mathrm{MnO}$ oxides prepared by sol-gel method," Solid State Ionics, vol. 138, no. 3-4, pp. 227-232, 2001.

[32] K. Kato and K.-I. Niihara, "Roles of polyethylene glycol in evolution of nanostructure in $\mathrm{TiO}_{2}$ coatings," Thin Solid Films, vol. 298, no. 1-2, pp. 76-82, 1997.

[33] A. J. Maira, J. M. Coronado, V. Augugliaro, K. L. Yeung, J. C. Conesa, and J. Soria, "Fourier transform infrared study of the performance of nanostructured $\mathrm{TiO}_{2}$ particles for the photocatalytic oxidation of gaseous toluene," Journal of Catalysis, vol. 202, no. 2, pp. 413-420, 2001.

[34] K. Hadjiivanov, "FTIR study of $\mathrm{CO}$ and $\mathrm{NH}_{3}$ co-adsorption on $\mathrm{YiO}_{2}$ (rutile)," Applied Surface Science, vol. 135, no. 1-4, pp. 331-338, 1998.

[35] H. Einaga, S. Futamura, and T. Ibusuki, "Heterogeneous photocatalytic oxidation of benzene, toluene, cyclohexene and cyclohexane in humidified air: comparison of decomposition behavior on photoirradiated $\mathrm{TiO}_{2}$ catalyst," Applied Catalysis B: Environmental, vol. 38, no. 3, pp. 215-225, 2002. 


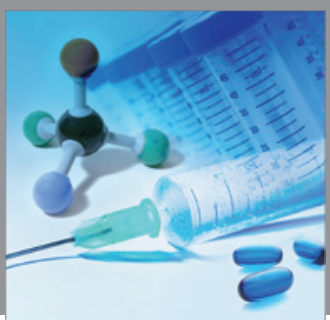

International Journal of

Medicinal Chemistry

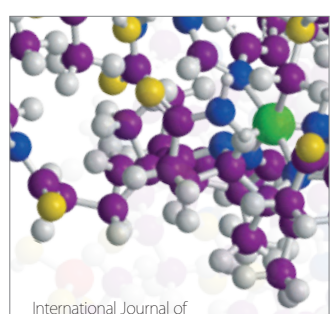

Carbohydrate Chemistry

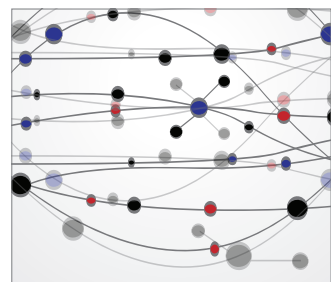

The Scientific World Journal
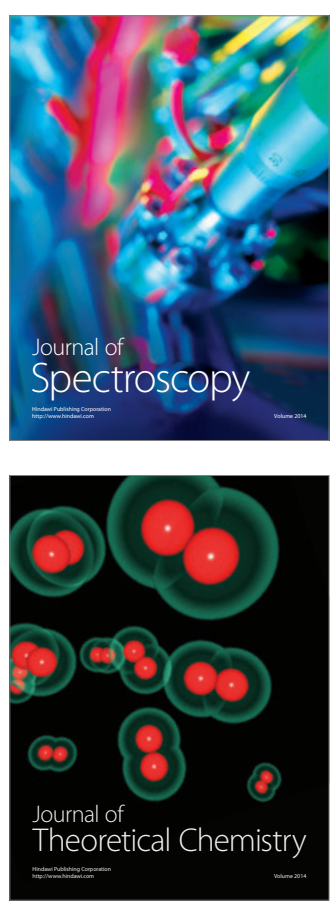
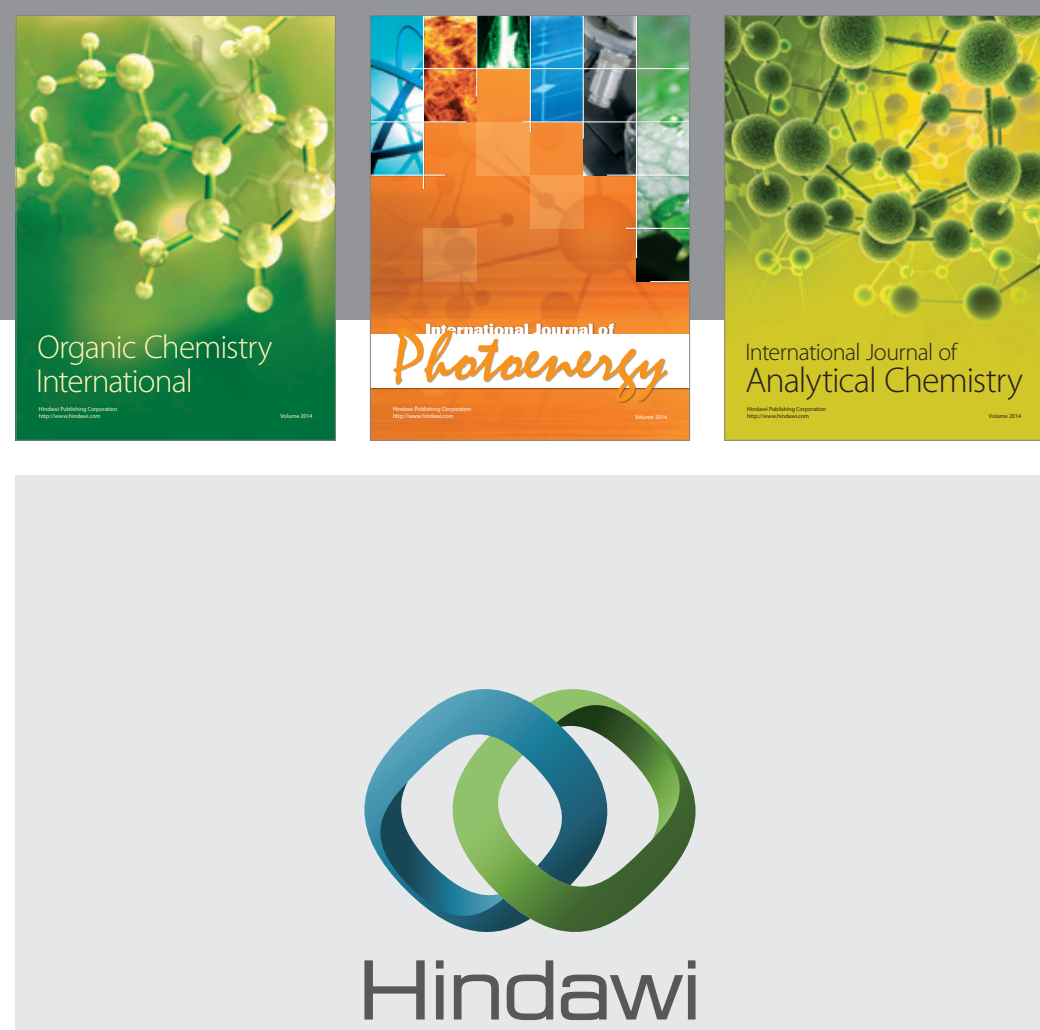

Submit your manuscripts at

http://www.hindawi.com
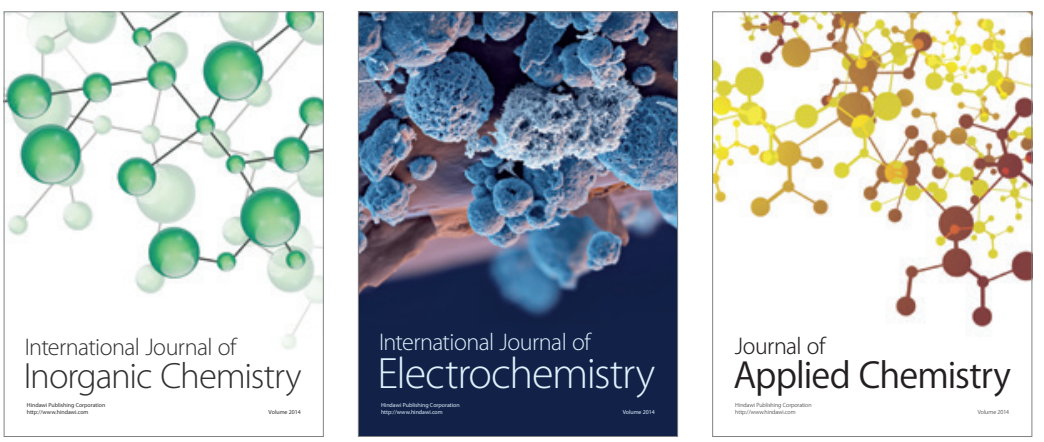

Journal of

Applied Chemistry
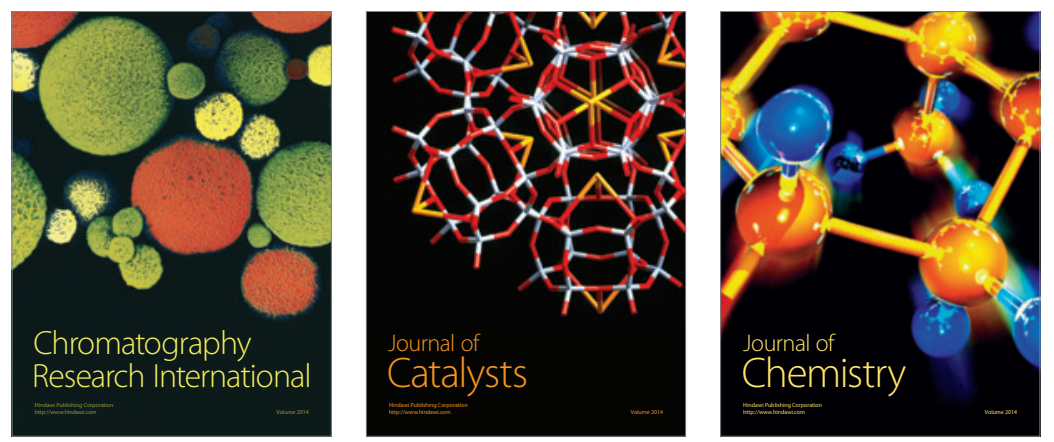
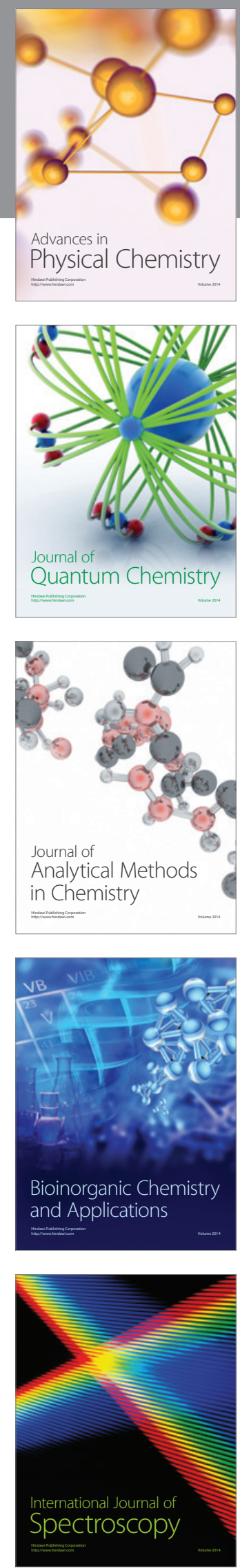